\title{
Comparison of the effect of control, presence of a skilled birth attendant and reflexotherapy on labour outcomes in terms of pain, duration of labour and birth satisfaction among primigravid women-a pilot study.
}

\author{
Mathew Jijimole ${ }^{1 *}$, Jaleel Abdul A ${ }^{2}$, Vijayaraghavan $\mathbf{R}^{3}$, Susila $\mathbf{C}^{4}$ \\ ${ }^{1}$ Department of Obstetrics and Gynaecological Nursing, Little Flower Hospital and Research Centre Angamaly, Kerala, \\ India \\ ${ }^{2}$ Department of Surgery, Karuna Medical College, Palakkad, Kerala, India \\ ${ }^{3}$ Department of Research, Saveetha University, Thandalam, Chennai, India \\ ${ }^{4}$ Bilroth College of Nursing, Maduravoyal, Chennai, India
}

\begin{abstract}
Background: Labour is the most poignant and fruitful moment in a woman's life. World Health Organization has emphasized on the necessity of incorporating complementary therapies by health professionals. International Confederation of Midwives has recommended labour support and integration of non-pharmacological measures for the effective management of women in labour.

Objective: To compare of the effect of control, presence of a skilled birth attendant and reflexotherapy on labour outcomes among primi gravid women in terms of pain, duration of labour and birth satisfaction.

Materials and methods: A true experimental design with systematic random sampling method was employed for the study. Forty five primigravid women in labour, 15 in each group, between 37 to $40 \mathrm{w}$ of gestation were included in the study after obtaining voluntary informed consent. The control group was given routine care in the labour room. Instructional, emotional and physical support with continuous presence from 3-4 cm of cervical dilatation till the end of third stage was ensured to the skilled birth attendant group. Application of reflexotherapy for $45 \mathrm{~min}$ from 3-4 cm of cervical dilatation was given to the reflexotherapy group. The tools used were numerical pain scale, behaviour response to pain assessment scale, partograph and birth satisfaction scale.

Results: Kruskal wallies one way ANOVA on ranks showed significant difference $(P \leq 0.001)$ between the three groups in pain for all the three stages of observation using the numerical pain scale and significant difference $(P \leq 0.05)$, between the three groups, in the postural response to pain in all the three stages of observation and for the facial, verbal and motor response to pain at 5-6 and 7-8 cm of cervical dilation. Kruskal wallies one way ANOVA on ranks showed no significant difference between the control, skilled birth attendant and reflexotherapy groups on duration of labour among the three groups and there was significant difference $(P \leq 0.007)$ in the post-delivery assessment of birth satisfaction.

Conclusion: These findings construe that reflexotherapy and skilled birth attendant are effective for positive labour outcomes in terms of pain and quality of birth experience.
\end{abstract}

Keywords: Reflexotherapy, Skilled birth attendant, Labour pain, Duration of labour, Birth satisfaction.

Accepted on September 6, 2018

\section{Introduction}

The omniscient and omnipotent creator of this universe designed the anatomy and physiology of the female human body in a way that, it is capable of natural child birth. Natural child birth is the birth of the baby through the vagina without medical interventions like anaesthesia and the use of forceps, vaccum extraction or caesarean section [1]. Women remain fully aware and totally mindful of the birthing process during an unmedicated natural birth. She is completely attuned to the baby in the out of the womb experience [2]. Labour although varies with the individual may be the most painful experience, any women may ever encounter [3]. Pain occurs with uterine contractions and in turn cervical dilation and effacement [4]. However this unpleasant sensation augments maternal catecholamine release and further adds to the emotional stress and likely to delay the process of labour. The apprehension related to pain brings in frequent demand of caesarean section 
[5]. At all India level the caesarean section rate has increased from $2.9 \%$ of the child birth in $1990-1993$ to $7.1 \%$ in $1998-1999$ and further rise to $8.5 \%$ in $2005-2006$ and a steady rise to $17.2 \%$ in $2015-2016$ [6]. Several interrelated aspects influence the high caesarean rate. Enhancing women's innate capacity to give birth is seldom made mandatory. A good number of health care facilities are unwilling to offer the informed choice of vaginal birth to women in certain circumstances [7].

World health organization defines traditional medicine (TM) as diverse health practices, approaches, knowledge and beliefs incorporating plant, animal, and mineral based medicines, spiritual therapies, manual techniques and exercises applied singularly or in combination to maintain well-being, as well as to treat, diagnose or prevent illness. TM is often termed "complementary", "alternative" or "non-conventional" medicine [8].

Many countries now recognize the need to develop a cohesive and integrative approach to health care that allows governments, health care practitioners and, most importantly, those who use health care services, to access Traditional and Complementary medicine in a safe, respectful, cost-efficient and effective manner. A global strategy to foster its appropriate integration, regulation and supervision will be useful to countries wishing to develop a proactive policy towards this important and often vibrant and expanding part of health care [9].

Reflexology is a science that deals with the principle that there are reflexes or zones running along the body which terminate in the feet and hands [10]. All systems and organs of the body are said to be reflected on the surface of the skin in particular on the hands and feet. Thus, by applying gentle pressure to these areas, help to relieve stress and muscular tension, induce deep relaxation, and promote the natural functioning of the body [11]. Reflexology stimulates the body into healing itself by improving circulation, reducing stress, pain and restoring natural balance [12]. During a labour reflexology session pressure is applied on the specific points on a woman's feet and hand to stimulate the pituitary glands and to induce the hormones needed to speed up the labour and to ease the pain [13].

Skilled birth attendant is a health professional who has been educated and trained to proficiency in the skills needed to manage normal (uncomplicated) pregnancies, child birth and immediate postnatal period in the identification management and referral of complicated cases. [14]. Historically and crossculturally, women have been attended and supported by other women during labour and birth. However, since the middle of the twentieth century, in many countries most women gave birth in hospital rather than at home and continuous support during labour has become the exception rather than the routine. Research has demonstrated that women benefit from and value the presence of a support person during labour, to provide psychological, physical, emotional, informational and practical support [15].
Bygone are the days, women in labour were surrounded by other women, kith and kin, in order to enhance her with practical assistance, relief, and emotional support. The purpose of this was to augment her capacity to handle the strain of labor. This culture is slowly getting vanished with the inception of institutionalized labour. Simultaneously there is introduction of complementary therapies like reflexotherapy, to help out the women in the process of labour. Hence the investigator has undertaken a study to compare the effect of control, presence of a skilled birth attendant and reflexotherapy on labour outcomes in terms of pain, duration of labour and birth satisfaction among primi gravid women.

\section{Materials and Methods}

\section{Objective}

To compare of the effect of control, presence of a skilled birth attendant and reflexotherapy on labour outcomes among primi gravid women in terms of pain, duration of labour and birth satisfaction.

\section{Research approach and research design}

Quantitative approach with true experimental design.

Participants: Forty five primi gravid women, 15 for the routine care group, 15 for the birth attendant group, and 15 for the reflexotherapy group, were taken using simple random sampling technique.

\section{Tool for data collection}

Demographic data sheet of primigravid women, numerical pain scale, behavior response to pain scale, partograph and birth satisfaction scale.

Inclusion and exclusion criteria: Primi gravid women who completed of $37 \mathrm{w}$ of gestation, with normal singleton pregnancy and vertex presentation, absence of medical and obstetric complications affecting normal labour, presence of no mental illness and ability to read and understand English or Malayalam were the criteria for inclusion. Primi gravid women with malpresentation, cephalopelvic disproportion. Ante partum haemorrhage, hydroamniosis, pre eclampsia, placenta previa and those on pain relieving medications were excluded from the study.

\section{Statistical analysis}

Kruskal wallies one way ANOVA on Ranks and Friedman one way RM ANOVA on Ranks for the comparison of labour pain, duration of labour, and birth satisfaction were used for statistical analysis.

\section{Procedure for data collection}

The approval for conducting the study was obtained from the institutional Human Ethics committee of Saveetha University $(003 / 07 / 2017 / \mathrm{IEC} / \mathrm{SU})$ and the administrator of Dhanya 

terms of pain, duration of labour and birth satisfaction among primigravid women-a pilot study

Hospital, Chalakudy, Kerala. Study is carried out in the months of September and October 2017. Random selection of three succeeding days a week for data collection and further random allotment of these three days of each week to routine care (control), skilled birth attendant and reflexology group was done.

Those in the control group were given routine care in the labour room. The investigator remained in the labour room as an observer.

To the skilled birth attendant group, instructional support was provided giving to each primi gravid woman a leaflet on labour and delivery, which put in plain words what is labour, the stages of labour, the signs of labour, the interventions considered as part of normal labour, and how to stay comfortable during the process of labour during pre-labour period and encouraged them to read it and clarify doubts in the prelabour period after obtaining voluntary informed consent. From 3-4 cm of cervical dilatation emotional support was offered by staying close to the primi gravid woman treating her with respect, being kind and gentle in dealing with her, clearing her doubts, addressing her by name, attempting to reduce her pain and anxiety, boosting her self-confidence, and distracting her during painful contractions. Physical support was rendered assisting the primi gravid woman in labour to meet the nutritional and elimination needs and helping her to reposition herself, which will facilitate her go through the process with more ease.

Foot reflexotherapy was applied for the third group at 3-4 cm of cervical dilatation on both the foot simultaneously for 45 min in the labour room after obtaining the voluntary informed consent at the time of admission. Reflexology session had 19 areas; 1. Preliminaries which included mild massage on the whole foot. This was followed by the application of pressure in the reflex centers related to 2. Pituitary gland, 3. Head, 4. Throat, thyroid and thymus gland 5. Shoulder area 6. Lung and heart area, 7. Back of the chest, 8. Bronchial area, 9. Diaphragm, oesophagus, stomach and pancreas 10. Spleen liver and gall bladder, 11. The small intestine 12. The large intestine,13. The lymphatic system, 14. The urinary bladder, 15. Uterus vagina, 16. Rectum.17. Shoulder, arm, hand, legs, elbow, hips, knee joint and spinal nerves, 18. The spinal column, 19. The solar plexus. After the completion of the whole of the foot, in a sequence and systematic manner, pressure was applied in the reflex centres related to pituitary located on the centre of the big toe, uterus on both the feet in the hollows under the inner ankle bones or the indented region between the inner ankle and the sole and solar plexus in the border of upper and middle one third of the sole where foot wrinkle is created, when the sole bends.

Assessment of all the three groups was done at the same timing. Numerical pain scale and behavior response to pain scale was used to assess the labour pain after $30 \mathrm{~min}$, at 5-6 and $7-8 \mathrm{~cm}$ of cervical dilatation during contractions. Partograph was maintained in order to measure the duration of labour. On the second postpartum day, satisfaction in labour was assessed using birth satisfaction scale.

\section{Results}

\section{The demographic characteristics of primi gravid women}

Most of the participants in the control (73\%) skilled birth attendant $(67 \%)$ and reflexotherapy group $(80 \%)$ belonged to the age group between 21-30 y (Table 1). The educational qualification of majority in the control $(60 \%)$, skilled birth attendant $(67 \%)$ and reflexotherapy $(60 \%)$ groups were graduation and postgraduation. About $40 \%$ in the control, $53 \%$ in the skilled birth attendant and $40 \%$ in the reflexotherapy group were housewives. The gestational age was $39-40 \mathrm{w}$ for $40 \%$ control, 53\% skilled birth attendant and $47 \%$ reflexotherapy group. All the participants in all the three groups had wanted pregnancy. The pre pregnant weight was between $41-50 \mathrm{~kg}$ and $51-60 \mathrm{~kg}(40 \%$ and $47 \%),(40 \%$ and $53 \%),(47 \%$ and $53 \%)$ for the control, skilled birth attendant and reflexotherapy group respectively. The height of the most of the participants in the control $(60 \%)$, skilled birth attendant (70\%) and reflexotherapy (70\%) were between $151 \mathrm{~cm}-160$ $\mathrm{cm}$. About $93 \%$ in the control, $93 \%$ in the skilled birth attendant and $87 \%$ in the reflexotherapy group had their pre pregnant body mass index between 18.51-24.9. About $87 \%$ of control, $93 \%$ of skilled birth attendant and $80 \%$ of reflexotherapy group had no prenatal classes. The onset of labour of all the participants $(100 \%)$ was induced and the induction was done with the use of oxytocin.

\section{Comparison of the effectiveness of the control, skilled birth attendant, reflexotherapy on labour pain}

In this study pain intensity was measured using numerical pain scale. The assessment of pain was done at $30 \mathrm{~cm}$ after the intervention and at $5-6 \mathrm{~cm}$ and $7-8 \mathrm{~cm}$ of cervical dilation. Kruskal wallies one way ANOVA on Ranks showed significant difference between the three groups in the in all the three stages of observation of pain using the numerical pain scale $(\mathrm{P}$ $\leq$ 0.001) (Table 2). Students Newman-Keul method showed significant difference in the pain score between the control and reflexotherapy group $(\mathrm{P} \leq 0.001)$, skilled birth attendant and reflexotherapy group $(\mathrm{P} \leq 0.001)$ and no significant difference between control and skilled birth attendant group. Friedman one way RM ANOVA on ranks showed significant changes within each group at different stages of observation $(\mathrm{P} \leq$ 0.001).

\section{Comparison of the effectiveness of control, skilled birth attendant and reflexotherapy groups on behavior response to labour pain}

Assessment of behaviour response to pain was done using a scale to assess the behavior response to pain. Kruskal wallies one way ANOVA on Ranks showed no significant difference between the three groups in the facial, verbal and motor response to pain after $30 \mathrm{~m}$ of intervention (Table 3). Significant difference $(\mathrm{P} \leq 0.05)$, was found between the three groups in the postural response to pain in all the three stages of 
observation and for the facial, verbal and motor response to pain at $5-6 \mathrm{~cm}$ and $7-8 \mathrm{~cm}$ of cervical dilation. Students Newman-Keul method showed no significant difference in the pain score between the control and reflexotherapy group, control and skilled birth attendant group and skilled birth attendant and reflexotherapy group in the facial, verbal, postural and motor response to pain after $30 \mathrm{~m}$ of intervention. Significant difference $(P \leq 0.05)$, was found between the control and reflexotherapy group $(\mathrm{P} \leq 0.05)$, skilled birth attendant and reflexotherapy group $(\mathrm{P} \leq 0.05)$ and no significant difference between control and skilled birth attendant group in the facial, verbal postural and motor response to pain at $5-6 \mathrm{~cm}$ and $7-8 \mathrm{~cm}$ of cervical dilation.

\section{Comparison of the effectiveness of control, skilled birth attendant reflexotherapy on duration of labour}

Kruskal wallies one way ANOVA on Ranks showed no significant difference between the control, Skilled birth attendant and Reflexotherapy groups on duration of Labour in the first stage $(\mathrm{P}=0.117)$, second stage $(\mathrm{P}=168)$ and third stage $(\mathrm{P}=0.083)$ and in the total duration of labour $(\mathrm{P}=0.110)$ (Table 4).

\section{Comparison of the effectiveness of control, skilled birth attendant reflexotherapy on birth satisfaction}

Kruskal wallies one way ANOVA on Ranks showed significant difference between the control, skilled birth attendant and reflexotherapy groups in the post-delivery assessment of birth satisfaction $(P \leq 0.007)$. Students Newman-Keul method showed significant difference in the birth satisfaction between the control and reflexotherapy group $(\mathrm{P} \leq 0.005)$, skilled birth attendant and reflexotherapy group $(\mathrm{P} \leq 0.023)$ and control and skilled birth attendant group $(\mathrm{P} \leq 0.016)$. Kruskal wallies one way ANOVA on Ranks showed significant difference between the control, Skilled birth attendant and Reflexotherapy groups in the post-delivery assessment of birth satisfaction $(\mathrm{P} \leq 0.007)$ (Table 5).

Table 1. Description of primi gravid women according to their demographic characteristics.

\begin{tabular}{|c|c|c|c|c|c|c|c|c|c|}
\hline \multirow[t]{2}{*}{ S. no. } & \multirow{2}{*}{$\begin{array}{l}\text { Demographic. } \\
\text { characteristics }\end{array}$} & \multirow[t]{2}{*}{ Categories } & \multicolumn{2}{|c|}{ (CO) } & \multicolumn{2}{|c|}{ (SKB) } & \multicolumn{2}{|c|}{ (RT) } & \multirow[t]{2}{*}{ Statistics } \\
\hline & & & $\begin{array}{l}N \\
15\end{array}$ & $=\%$ & $\begin{array}{l}N \\
15\end{array}$ & $=\%$ & $\begin{array}{l}N \\
15\end{array}$ & $=\%$ & \\
\hline \multirow[t]{4}{*}{1} & Age & $18-20 y$ & 1 & 7 & 2 & 13 & 0 & 0 & \\
\hline & & $21-25$ y & 6 & 40 & 7 & 47 & 8 & 53 & \\
\hline & & $26-30$ y & 5 & 33 & 3 & 20 & 4 & 27 & \\
\hline & & $31-35 y$ & 3 & 20 & 3 & 20 & 3 & 20 & \\
\hline \multirow[t]{5}{*}{2} & Education & $\begin{array}{l}\text { Postgraduat } \\
\text { e }\end{array}$ & 3 & 20 & 3 & 20 & 4 & 27 & \\
\hline & & $\begin{array}{l}\text { Under } \\
\text { graduate }\end{array}$ & 6 & 40 & 7 & 47 & 5 & 33 & \\
\hline & & $\begin{array}{l}\text { Higher } \\
\text { secondary }\end{array}$ & 4 & 27 & 3 & 20 & 2 & 13 & \\
\hline & & High school & 2 & 13 & 2 & 13 & 4 & 27 & \\
\hline & & $\begin{array}{l}\text { Middle } \\
\text { school }\end{array}$ & 0 & 0 & 0 & 0 & 0 & 0 & \\
\hline \multirow[t]{4}{*}{3} & Occupation & Professional & 3 & 20 & 4 & 27 & 4 & 27 & \\
\hline & & $\begin{array}{l}\text { Technical } \\
\text { worker }\end{array}$ & 5 & 33 & 3 & 20 & 3 & 20 & \\
\hline & & $\begin{array}{l}\text { DAILY } \\
\text { WAGE } \\
\text { WORKER }\end{array}$ & 1 & 7 & 0 & 0 & 2 & 13 & \\
\hline & & House wife & 6 & 40 & 8 & 53 & 6 & 40 & \\
\hline \multirow[t]{3}{*}{4} & Gestational age & $37-38 w$ & 4 & 27 & 3 & 20 & 4 & 27 & $\begin{array}{l}\text { As it was a pilot study and the sample size was smaller c2 } \\
\text { test was not carried }\end{array}$ \\
\hline & & $38-39 w$ & 5 & 33 & 4 & 27 & 4 & 27 & Out \\
\hline & & $39-40 w$ & 6 & 40 & 8 & 53 & 7 & 47 & \\
\hline 5 & Type of pregnancy & Wanted & 15 & 100 & 15 & 100 & 15 & 100 & \\
\hline
\end{tabular}


Comparison of the effect of control, presence of a skilled birth attendant and reflexotherapy on labour outcomes in terms of pain, duration of labour and birth satisfaction among primigravid women-a pilot study

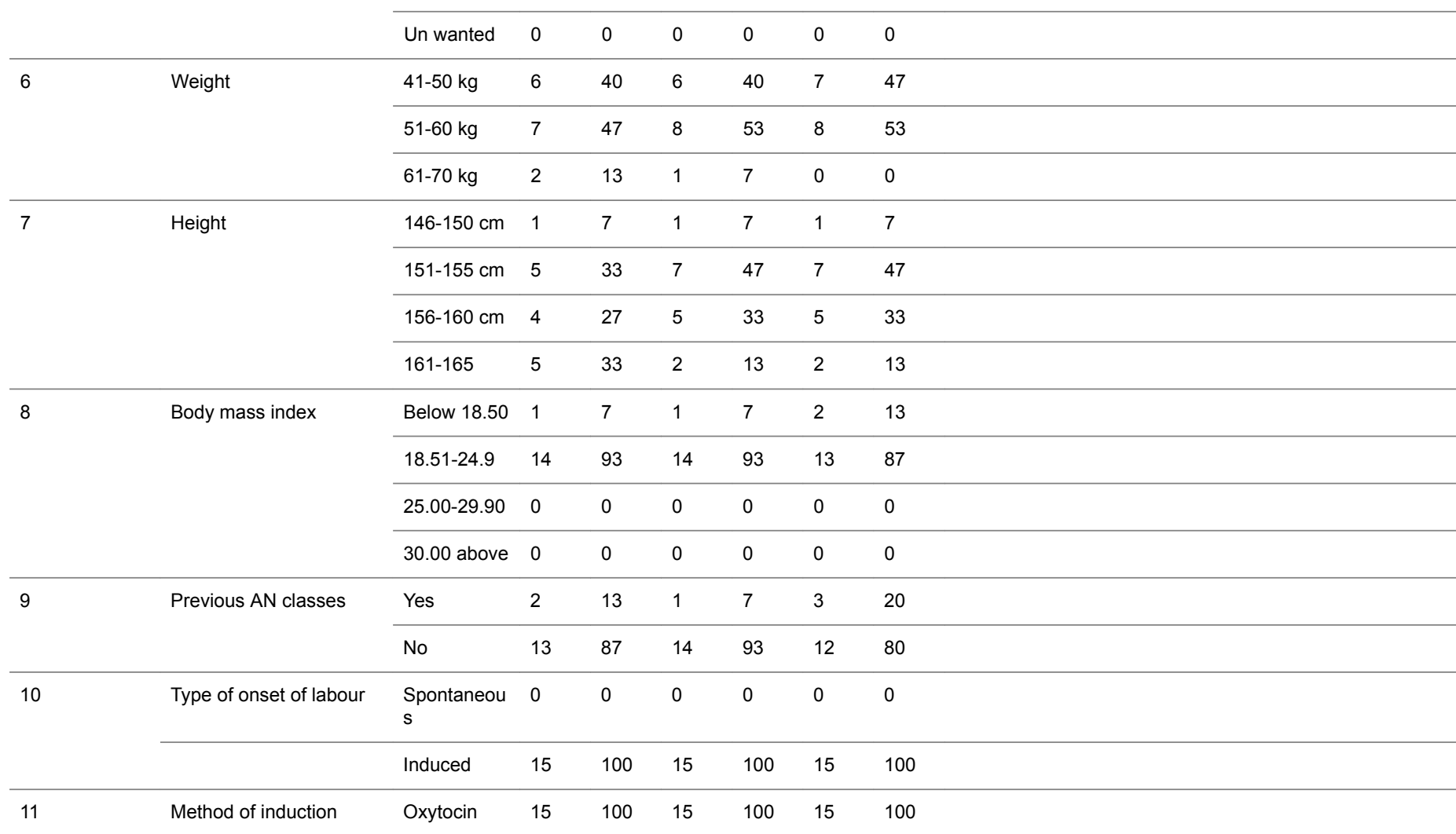

$\mathrm{N}=45$; Co: Control group; SKB: Skilled Birth Attendant; RT: Reflexotherapy.

Table 2. Comparison of the effectiveness of control, skilled birth attendant and reflexotherapy groups on labour pain.

\begin{tabular}{|c|c|c|c|c|}
\hline SI. no & Parameter & Group & Median & Kruskal wallies one way ANOVA on Ranks \\
\hline \multirow[t]{3}{*}{1} & & $\mathrm{CO}-30$ & $3.00(2.00,4.00)$ & $\mathrm{H}=10.079$ \\
\hline & & SKB-30 & $3.00(2.00,3.00)$ & $d f=2$ \\
\hline & & RT-30 & $2.00(1.00,2.00)$ & $P \leq 0.006$ \\
\hline \multirow[t]{4}{*}{2} & Labour pain at $5 \mathrm{~cm}-6 \mathrm{~cm}$ of cervical & CO-5-6 & $5.00(4.00,7.00)$ & $\mathrm{H}=19.323$ \\
\hline & & & & $d f=2$ \\
\hline & & SKB-5-6 & $5.00(4.00,7.00)$ & $P \leq 0.001$ \\
\hline & & RT-5-6 & $3.00(2.00,4.00)$ & \\
\hline \multirow[t]{5}{*}{3} & Labour pain at $7 \mathrm{~cm}-8 \mathrm{~cm}$ of cervical & CO-7-8 & $9.00(8.00,9.00)$ & $\mathrm{H}=26.919$ \\
\hline & & & & $d f=2$ \\
\hline & & SKB-7-8 & $8.00(7.00,9.00)$ & $P \leq 0.001$ \\
\hline & & RT-7-8 & $6.00(6.00,7.00)$ & \\
\hline & & Group & $\begin{array}{l}\text { Median } \\
\text { percentile) }\end{array}$ & $\begin{array}{l}\text { Friedman one way RM } \\
\text { ANOVA on ranks }\end{array}$ \\
\hline \multirow[t]{5}{*}{1} & Labour pain in control group & Co-30 & $3.00(2.00,4.00)$ & Co-30 vs. 5-6 S \\
\hline & & & & $d f=2$ \\
\hline & & Co-5-6 & $5.00(4.00,7.00)$ & Co-30 vs. 7-8 S \\
\hline & & & & $P \leq 0.001$ \\
\hline & & Co-7-8 & $9.00(8.00,9.00)$ & Co-5-6 vs. 7-8 S \\
\hline
\end{tabular}




\begin{tabular}{|c|c|c|c|c|c|}
\hline \multirow[t]{5}{*}{2} & \multirow[t]{5}{*}{ Labour pain in skilled birth attendant } & SKB-30 & $3.00(2.00,3.00)$ & $x^{2}=30.00$ & SKB-30 vs. 5-6 S \\
\hline & & \multicolumn{4}{|c|}{$d f=2$} \\
\hline & & SKB-5-6 & $5.00(4.00,7.00)$ & & SKB-30 vs. 7-8 S \\
\hline & & \multicolumn{4}{|c|}{$P \leq 0.001$} \\
\hline & & SKB-7-8 & $8.00(7.00,9.00)$ & & SKB-5-6 vs. 7-8 S \\
\hline \multirow[t]{4}{*}{3} & \multirow[t]{4}{*}{ Labour pain in reflexotherapy group } & RT-30 & $2.00(1.00,2.00)$ & $x^{2}=28.7$ & RT-30 Vs. 5-6 S \\
\hline & & \multicolumn{4}{|c|}{$d f=2$} \\
\hline & & RT-5-6 & $3.00(2.00,4.00)$ & $P \leq 0.001$ & RT-30 vs. 7-8 S \\
\hline & & RT-7-8 & $6.00(6.00,7.00)$ & & RT-5-6 vs. 7-8 S \\
\hline
\end{tabular}

N=45; Co: Control group; SKB: Skilled Birth Attendant; RT: Reflexotherapy; S: Significant; N: Non-significant

Table 3. Comparison of the effectiveness of control, skilled birth attendant and reflexotherapy groups on behavior response to labour pain.

\begin{tabular}{|c|c|c|c|c|c|}
\hline SI. no & Parameter & Group & Median (25 and 75 percentile) & Kruskal wallies one way ANOVA on & Rank \\
\hline \multirow[t]{19}{*}{1} & Facial & CO-30 & $1.00(1.00 .1 .00)$ & $\mathrm{H}=3.482$ & \\
\hline & & CO- 5-6 & $1.00(0.00,1.00)$ & $\mathrm{Df}=2$ & \\
\hline & & CO- 7-8 & $0.00(0.00 .1 .00)$ & $P=0.175$ & \\
\hline & & SKB-30 & $2.00(1.00,2.00)$ & $\mathrm{H}=9.454$ & \\
\hline & & SKB- 5-6 & $2.00(1.00,2.00)$ & $\mathrm{Df}=2$ & \\
\hline & & SKB-7-8 & $1.00(1.00,1.00)$ & $P=0.009$ & \\
\hline & & RT- 30 & $3.00(2.00,3.00)$ & $\mathrm{H}=6.590$ & \\
\hline & & RT- 5-6 & $3.00(2.00,3.00)$ & $\mathrm{Df}=2$ & \\
\hline & & RT- 7-8 & $2.00(1.00,2.00)$ & $P=0.037$ & \\
\hline & & Group & Median ( 25 and 75 percentile) & $\begin{array}{l}\text { Friedman one way RM ANOVA on } \\
\text { ranks }\end{array}$ & \\
\hline & & CO-30 & $1.00(1.00 .1 .00)$ & $x^{2}=19.875$ & $\begin{array}{l}\mathrm{CO}-30 \text { Vs CO- } 5-6 \\
\mathrm{~S}\end{array}$ \\
\hline & & CO- 5-6 & $2.00(1.00,2.00)$ & $d f=2$ & $\begin{array}{l}\mathrm{CO}-30 \text { Vs } \mathrm{CO}-7-8 \\
\mathrm{~S}\end{array}$ \\
\hline & & CO- 7-8 & $3.00(2.00,3.00)$ & $P \leq 0.001$ & $\begin{array}{l}\text { CO- } 5 \text {-6Vs CO-7-8 } \\
\text { S }\end{array}$ \\
\hline & & SKB-30 & $1.00(0.00,1.00)$ & $x^{2}=23.698$ & $\begin{array}{l}\text { SKB-30 Vs SKB- } \\
4-5 \mathrm{~S}\end{array}$ \\
\hline & & SKB- 5-6 & $2.00(1.00,2.00)$ & $\mathrm{df}=2$ & $\begin{array}{l}\text { SKB-30 } \quad V s \\
\text { SKB-7-8 S }\end{array}$ \\
\hline & & SKB-7-8 & $3.00(2.00,3.00)$ & $P \leq 0.001$ & $\begin{array}{l}\text { SKB- } \quad 5-6 \quad \text { Vs } \\
\text { SKB-7-8 S }\end{array}$ \\
\hline & & RT- 30 & $0.00(0.00 .1 .00)$ & $x^{2}=0.600$ & $\begin{array}{l}\text { RT- } 30 \text { Vs RT- } 5-6 \\
\text { N S }\end{array}$ \\
\hline & & RT- 5-6 & $1.00(1.00,1.00)$ & $\mathrm{df}=2$ & $\begin{array}{l}\text { RT- } 30 \text { Vs RT- } 7-8 \\
\text { S }\end{array}$ \\
\hline & & RT- 7-8 & $2.00(1.00,2.00)$ & $P \leq 0.001$ & $\begin{array}{l}\text { RT- 5-6 Vs RT- 7-8 } \\
\text { S }\end{array}$ \\
\hline SI. no & Parameter & Group & Median ( 25 and 75 percentile) & Kruskal wallies one way ANOVA on & Ranks \\
\hline
\end{tabular}


Comparison of the effect of control, presence of a skilled birth attendant and reflexotherapy on labour outcomes in terms of pain, duration of labour and birth satisfaction among primigravid women-a pilot study

\begin{tabular}{|c|c|c|c|c|c|}
\hline \multirow[t]{20}{*}{2} & \multirow[t]{20}{*}{ Verbal } & $\mathrm{CO}-30$ & $1.00(0.00 .1 .00)$ & \multicolumn{2}{|l|}{$H=3.357$} \\
\hline & & CO- 5-6 & $1.00(0.00,2.00)$ & \multicolumn{2}{|l|}{$\mathrm{Df}=2$} \\
\hline & & CO- 7-8 & $0.00(0.00 .1 .00)$ & \multicolumn{2}{|l|}{$P=0.187$} \\
\hline & & SKB-30 & $1.00(1.00,2.00)$ & \multicolumn{2}{|l|}{$H=8.895$} \\
\hline & & SKB- 5-6 & $1.00(1.00,2.00)$ & \multicolumn{2}{|l|}{$\mathrm{Df}=2$} \\
\hline & & SKB-7-8 & $1.00(0.00,1.00)$ & \multicolumn{2}{|l|}{$P=0.012$} \\
\hline & & RT- 30 & $3.00(2.00,3.00)$ & \multicolumn{2}{|l|}{$\mathrm{H}=7.697$} \\
\hline & & & & \multicolumn{2}{|l|}{$\mathrm{Df}=2$} \\
\hline & & RT- 5-6 & $3.00(2.00,3.00)$ & \multicolumn{2}{|l|}{$P=0.021$} \\
\hline & & RT- 7-8 & $2.00(1.00,2.00)$ & & \\
\hline & & Group & Median (25 and 75 ) percentile & \multicolumn{2}{|l|}{$\begin{array}{l}\text { Friedman one way RM ANOVA on } \\
\text { ranks }\end{array}$} \\
\hline & & CO-30 & $1.00(0.00 .1 .00)$ & $x 2=25.000$ & $\begin{array}{l}\mathrm{CO}-30 \text { Vs CO- } 5-6 \\
\mathrm{~S}\end{array}$ \\
\hline & & CO- 5-6 & $1.00(1.00,2.00)$ & $d f=2$ & $\begin{array}{l}\mathrm{CO}-30 \text { Vs CO-7-8 } \\
\mathrm{S}\end{array}$ \\
\hline & & CO- 7-8 & $3.00(2.00,3.00)$ & $P \leq 0.001$ & $\begin{array}{l}\text { CO- } 5-6 V s \text { CO-7-8 } \\
\text { S }\end{array}$ \\
\hline & & SKB-30 & $1.00(0.00,2.00)$ & $x^{2}=20.860$ & $\begin{array}{l}\text { SKB-30 Vs SKB- } \\
4-5 \mathrm{~S}\end{array}$ \\
\hline & & SKB- 5-6 & $1.00(1.00,2.00)$ & $d f=2$ & $\begin{array}{l}\text { SKB-30 } \\
\text { SKB-7-8 S }\end{array}$ \\
\hline & & SKB-7-8 & $3.00(2.00,3.00)$ & $P \leq 0.001$ & $\begin{array}{ll}\text { SKB- } \quad 5-6 & V s \\
\text { SKB-7-8 S } & \end{array}$ \\
\hline & & RT- 30 & $0.00(0.00 .1 .00)$ & $x 2=26.92$ & $\begin{array}{l}\text { RT- } 30 \text { Vs RT- 5-6 } \\
\text { N S }\end{array}$ \\
\hline & & RT- 5-6 & $1.00(0.00,1.00)$ & $d f=2$ & $\begin{array}{l}\text { RT- } 30 \text { Vs RT- } 7-8 \\
\text { S }\end{array}$ \\
\hline & & RT- 7-8 & $2.00(1.00,2.00)$ & $P \leq 0.001$ & $\begin{array}{l}\text { RT- 5-6 Vs RT- 7-8 } \\
\text { S }\end{array}$ \\
\hline SI. no & Parameter & Group & Median ( 25 and 75 percentile) & \multicolumn{2}{|c|}{ Kruskal wallies one way ANOVA on Ranks } \\
\hline \multirow[t]{11}{*}{3} & Postural & CO-30 & $1.00(0.00 .1 .00)$ & \multicolumn{2}{|l|}{$\mathrm{H}=6.479$} \\
\hline & & co- 5-6 & $1.00(0.00,2.00)$ & \multicolumn{2}{|l|}{$\mathrm{Df}=2$} \\
\hline & & CO- 7-8 & $0.00(0.00 .1 .00)$ & \multicolumn{2}{|l|}{$P=0.039$} \\
\hline & & SKB-30 & $2.00(1.00,2.00)$ & \multicolumn{2}{|l|}{$\mathrm{H}=13.055$} \\
\hline & & SKB- 5-6 & $2.00(1.00,2.00)$ & \multicolumn{2}{|l|}{$\mathrm{Df}=2$} \\
\hline & & SKB-7-8 & $1.00(1.00,1.00)$ & \multicolumn{2}{|l|}{$P=0.001$} \\
\hline & & RT- 30 & $3.00(2.00,3.00)$ & \multicolumn{2}{|l|}{$H=13.515$} \\
\hline & & RT- 5-6 & $3.00(2.00,3.00)$ & $\mathrm{Df}=2$ & \\
\hline & & RT- 7-8 & $2.00(1.00,2.00)$ & $P=0.001$ & \\
\hline & & Group & Median (25\& 75$)$ percentile & $\begin{array}{l}\text { Friedman one way RM ANOVA on } \\
\text { ranks }\end{array}$ & \\
\hline & & CO-30 & $1.00(0.00 .1 .00)$ & $x^{2}=23.059$ & $\begin{array}{l}\mathrm{CO}-30 \text { Vs CO- } 5-6 \\
\mathrm{~S}\end{array}$ \\
\hline
\end{tabular}




\begin{tabular}{|c|c|c|c|}
\hline CO- 5-6 & $2.00(1.00,2.00)$ & $d f=2$ & $\begin{array}{l}\text { CO-30 Vs } \\
\text { S }\end{array}$ \\
\hline CO- 7-8 & $3.00(2.00,3.00)$ & $P \leq 0.001$ & $\begin{array}{l}\text { CO- } 5 \text {-6Vs CO-7-8 } \\
\text { S }\end{array}$ \\
\hline SKB-30 & $1.00(0.00,2.00)$ & $x 2=22.429$ & $\begin{array}{l}\text { SKB-30 Vs SKB- } \\
4-5 \mathrm{~S}\end{array}$ \\
\hline SKB- 5-6 & $2.00(1.00,2.00)$ & $\mathrm{df}=2$ & $\begin{array}{ll}\text { SKB-30 } & V s \\
\text { SKB-7-8 S } & \end{array}$ \\
\hline SKB-7-8 & $3.00(2.00,3.00)$ & $P \leq 0.001$ & $\begin{array}{lll}\text { SKB- } \quad 5-6 & \text { Vs } \\
\text { SKB-7-8 S }\end{array}$ \\
\hline RT- 30 & $0.00(0.00 .1 .00)$ & $x^{2}=25.765$ & $\begin{array}{l}\text { RT- } 30 \text { Vs RT- 5-6 } \\
\text { N S }\end{array}$ \\
\hline RT- 5-6 & $1.00(1.00,1.00)$ & $d f=2$ & $\begin{array}{l}\text { RT- } 30 \text { Vs RT- } 7-8 \\
\text { S }\end{array}$ \\
\hline RT- 7-8 & $2.00(1.00,2.00)$ & $P \leq 0.001$ & $\begin{array}{l}\text { RT- 5-6 Vs RT- 7-8 } \\
\text { S }\end{array}$ \\
\hline
\end{tabular}

\begin{tabular}{|c|c|c|c|c|c|}
\hline SI. no & Parameter & Group & Median (25 and75 percentile) & Kruskal wallies one way ANOVA on & Ranks \\
\hline \multirow[t]{19}{*}{4} & Motor & CO-30 & $1.00(1.00 .2 .00)$ & $\mathrm{H}=4.937$ & \\
\hline & & CO- 5-6 & $1.00(1.00,1.00)$ & $D f=2$ & \\
\hline & & $\mathrm{CO}-7-8$ & $0.00(0.00 .1 .00)$ & $P=0.085$ & \\
\hline & & SKB-30 & $2.00(1.00,2.00)$ & $\mathrm{H}=13.187$ & \\
\hline & & SKB- 5-6 & $1.00(1.00,2.00)$ & $\mathrm{Df}=2$ & \\
\hline & & SKB-7-8 & $1.00(0.00,1.00)$ & $P=0.001$ & \\
\hline & & RT- 30 & $3.00(2.00,3.00)$ & $H=8.523$ & \\
\hline & & RT- 5-6 & $3.00(2.00,3.00)$ & $\mathrm{Df}=2$ & \\
\hline & & RT- 7-8 & $2.00(1.00,2.00)$ & $P=0.014$ & \\
\hline & & Group & Median (25 \& 75) percentile & $\begin{array}{l}\text { Friedman one way RM ANOVA on } \\
\text { ranks }\end{array}$ & \\
\hline & & $\mathrm{CO}-30$ & $1.00(1.00 .2 .00)$ & $x 2=22.50$ & $\begin{array}{l}\text { CO-30 Vs CO- } 5-6 \\
\mathrm{~s}\end{array}$ \\
\hline & & CO- 5-6 & $2.00(1.00,2.00)$ & $\mathrm{df}=2$ & $\begin{array}{l}\text { CO-30 Vs } \quad \text { CO-7-8 } \\
\mathrm{S}\end{array}$ \\
\hline & & CO- 7-8 & $3.00(2.00,3.00)$ & $P \leq 0.001$ & $\begin{array}{l}\text { CO- } 5 \text {-6Vs CO-7-8 } \\
\mathrm{S}\end{array}$ \\
\hline & & SKB-30 & $1.00(1.00,1.00)$ & $x 2=22.00$ & $\begin{array}{l}\text { SKB-30 Vs SKB- } \\
4-5 \mathrm{~S}\end{array}$ \\
\hline & & SKB- 5-6 & $1.00(1.00,2.00)$ & $\mathrm{df}=2$ & $\begin{array}{l}\text { SKB-30 } \\
\text { SKB-7-8 S }\end{array}$ \\
\hline & & SKB-7-8 & $3.00(2.00,3.00)$ & $P \leq 0.001$ & $\begin{array}{l}\text { SKB- } \quad 5-6 \quad \text { Vs } \\
\text { SKB-7-8 S }\end{array}$ \\
\hline & & RT- 30 & $0.00(0.00 .1 .00)$ & $x 2=19.91$ & $\begin{array}{l}\text { RT- } 30 \text { Vs RT- 5-6 } \\
\text { N S }\end{array}$ \\
\hline & & RT- 5-6 & $1.00(0.00,1.00)$ & $\mathrm{df}=2$ & $\begin{array}{l}\text { RT- } 30 \text { Vs RT- } 7-8 \\
\text { S }\end{array}$ \\
\hline & & RT- 7-8 & $2.00(1.00,2.00)$ & $P \leq 0.001$ & $\begin{array}{l}\text { RT- 5-6 Vs RT- 7-8 } \\
\text { S }\end{array}$ \\
\hline
\end{tabular}


Comparison of the effect of control, presence of a skilled birth attendant and reflexotherapy on labour outcomes in terms of pain, duration of labour and birth satisfaction among primigravid women-a pilot study

N=45; Co: Control group; SKB: Skilled Birth Attendant; RT: Reflexotherapy; S: Significant; N: Non-significant.

Table 4. Comparison of the effectiveness of control, skilled birth attendant and reflexotherapy groups on duration of labour.

\begin{tabular}{|c|c|c|c|c|}
\hline SI. no & Parameter & Group & Median (25 and 75 percentile) & $\begin{array}{l}\text { Kruskal wallies one way ANOVA } \\
\text { on Ranks }\end{array}$ \\
\hline \multirow[t]{3}{*}{1} & Duration of labour in I stage & $\mathrm{CO}$ & $5.000(3.150,5.300)$ & $\mathrm{H}=4.83$ \\
\hline & & SKB & $4.300(3.450,5.300)$ & $\mathrm{Df}=2$ \\
\hline & & RT & $4.000(3.300,4.450)$ & $P=0.117$ \\
\hline \multirow[t]{3}{*}{2} & Duration of labour in II stage & $\mathrm{CO}$ & $30.000(26.000,35.000)$ & $H=3.564$ \\
\hline & & SKB & $28.000(25.000,30.000)$ & $\mathrm{Df}=2$ \\
\hline & & RT & $5.000(20.000,30.000)$ & $P=168$ \\
\hline \multirow[t]{3}{*}{3} & Duration of labour in III stage & $\mathrm{CO}$ & $10.000(9.000,11.000)$ & $\mathrm{H}=4.978$ \\
\hline & & SKB & $10.000(9.000,11.000)$ & $\mathrm{Df}=2$ \\
\hline & & RT & $9.000(8.000,10.000)$ & $P=0.083$ \\
\hline \multirow[t]{3}{*}{4} & Duration of labour in III stage & $\mathrm{CO}$ & $5.400(3.450,6.110)$ & $\mathrm{H}=4.412$ \\
\hline & & SKB & $5.060(4.230,6.090)$ & $\mathrm{Df}=2$ \\
\hline & & RT & $4.300(4.000,5.080)$ & $P=0.110$ \\
\hline
\end{tabular}

N=45; Co: Control group; SKB: Skilled Birth Attendant; RT: Reflexotherapy.

Table 5. Comparison of the effectiveness control, skilled birth attendant and reflexotherapy groups on birth satisfaction.

\begin{tabular}{|c|c|c|c|c|c|}
\hline SI. no & Parameter & Group & $\begin{array}{l}\text { Median (25 and } \\
\text { percentile) }\end{array}$ & 75 & $\begin{array}{l}\text { Kruskal } \\
\text { wallies } \\
\text { one way } \\
\text { ANOVA } \\
\text { on Ranks }\end{array}$ \\
\hline \multirow[t]{3}{*}{3} & Birth satisfaction & CO-post & $33.00(26.00,36.00)$ & & $\mathrm{H}=9.907$ \\
\hline & & SKB-post & $37.00(31.00,43.00)$ & & $\mathrm{Df}=2$ \\
\hline & & RT-post & $4.00(36.00,46.00)$ & & $P=0.007$ \\
\hline
\end{tabular}

N=45; Co: Control group; SKB: Skilled Birth Attendant; RT: Reflexotherapy.

\section{Discussion}

The findings of this study substantiate that presence of skilled birth attendant with the primi gravid women throughout the labour and application of reflexotherapy, a nonpharmacological method have significant effect in reducing the labour pain, and improving the birth satisfaction of the primi gravid women.

The present study revealed significant difference in the pain score between the control and reflexotherapy group, skilled birth attendant and reflexotherapy group and no significant difference between control and skilled birth attendant group in the numerical pain scale and in behaviour response to pain in terms of facial, verbal, postural and motor activities. These findings are in consistent with the following studies. A randomized clinical trial, enrolling 120 women in labour with 40 each in control, emotional support and reflexology group found that pain intensity at all the three stages of cervical dilatation was significantly lower in the reflexology group in comparison with the control and emotional support group [16]. Reflexology applied at $1-3 \mathrm{~cm}$ cervical dilatation and $5-7 \mathrm{~cm}$ cervical dilatation for $30 \mathrm{~min}$ revealed that the severity of labour pain in the experimental group was lower than the control group $(\mathrm{P}<0.01)$ [17]. Endorphin is body's natural pain relieving chemical. In reflexology the foot massage using hands releases endorphins and encephalins which further brings about reduction in pain and enhances the sense of wellbeing. The pressure on precise areas efficiently block pain neural pathways and by way of gate control mechanism. [18].

The present study discloses that there was significant reduction in behaviour response to pain in terms of facial, verbal, postural and motor response between control and reflexotherapy group and skilled birth attendant and reflexotherapy group whereas no significant difference between control and skilled birth attendant group at 5-6 and $7-8 \mathrm{~cm}$ of cervical dilatation. This result is congruent with Belal [19] who found that acupressure was significantly related to decrease in frowning or grimacing in labour and the study by Goweily [20] which showed a significant decrease in relation to behavioural response to labour pain among the reflexology group when compared to the control group.

This is due to the use of a compression massage technique on the feet or hands, release blocked energy or pain from organs, glands, as well as release toxin build up in the body. Reflexology relaxes the muscles, allowing the joints to gain mobility and release tight tension [21]. 
There was no significant difference between the control, skilled birth attendant and reflexology groups in the duration of labour. The finding of McNeill [22], showed no significant difference in the duration of labor between the two groups of reflexology and the control group but the people who had four or more reflexology treatments $(60 \mathrm{~min})$ had less duration of labor than control group. Dolatian et al. showed that the duration of labor in reflexology group is less than support and routine care groups. These differences in the findings may be attributable to the method or duration and the number of sessions of reflexology in labour. According to the studies, fear and anxiety increase adrenaline and nor adrenaline acting on the contrary to oxytocin. This can disturb uterine contractions and increase the duration of labor [23]. Reflexology by decreasing adrenaline and nor-adrenaline and increasing endorphins and inner oxytocin increase uterine muscle contractions and activities and can affect the duration of the labor [24]. In this study the reflexotherapy was performed only once and the result which showed no significant difference in the duration of labour must be owing to lack of repeated treatments.

Significant improvement in the birth satisfaction was observed both in the skilled birth attendant group and the reflexotherapy group in comparison with the control group similar to the findings of Abd [25] also reported that the use of reflexology in maternity care appears to demonstrate high levels of maternal and even staff satisfaction.

\section{Conclusion}

Researches are underway to unearth novel solutions and evidence based practice to make labour experience a satisfactory and fulfilling one. The promotion of birth as a normal physiological event and evidences based on the effectiveness of birth support and application of nonpharmacological methods may make the labour experiences more promising in particular for the first time mothers. The investigator propose that the complementary therapies which are cost effective, non-invasive and independent intervention could be integrated into the curriculum of nursing and midwifery education and hospitals may set aside complimentary and supportive therapies for the choice of the clients.

\section{Acknowledgement}

We would like to thank the participants for their cooperation in this study and acknowledge our gratitude to the authorities of the hospital for granting permission to conduct the study.

\section{References}

1. Natural child birth. Wikipedia https: //en.wikipedia.org/ wiki/Natural_childbirth accessed on 20th August 2017

2. Presti L. 7 Benefits of natural childbirth 2015. naturallysavvy.com/nest/the-benefits-of-natural-childbirth.

3. Iliadou M. Labour pain and pharmacological pain relief practice points. Health Sci J 2009; 3: 197-201.
4. Cheng YW, Hopkins LM, Caughey AB. How long is too long: does a prolonged second stage of labor in nulliparous women affect maternal and neonatal outcomes? Am J Obstet Gynecol 2004; 191: 933-938.

5. Charlton JE. Pain in pregnancy and labor. Core curriculum for professional education in pain (3rd Edn.). IASP Press USA 2005.

6. Radhakrishnan $\mathrm{T}$, Vasanthakumari KP, Babu PK. Increasing trend of caesarean rates in India: evidence from NFHS-4. J Med Sci Clin Res 2018; 5: 18.

7. Childbirth Connection. Why the US caesarean section rates are so high. A program of the National Partnership for Women \& Families 2016.

8. WHO Traditional Medicine Strategy 2002-2005. www.wpro.who.int/health../

book_who_traditional_medicine_strategy_2002_2005.pdf accessed on 20th August 2017.

9. WHO Taditional Medicine Strategy 2014-2013. www.who.int/medicines/publications/traditional/ trm_strategy14_23/en/

10. Kunz K, Kunz B. The complete guide to foot reflexology. Reflexology Research Project 1993.

11. Box D. The nurses handbook of complementary therapies (4th Edn.). Edinburgh: Bailliere Tindall 2006; 240-247.

12. Brazil A. Reflexology Room London 2015

13. Legare D. Reflexology for pregnancy and labor-babble 2011 https: //www.babble.com/pregnancy/reflexologypregnancy-labor/

14. Bettina U, Ghazna S, Adetoro A, Nynke VDB. Definitions and roles of a skilled birth attendant: a mapping exercise from four South-Asian countries. Acta Obstet Gynecol Scand 2013; 92: 1063-1069.

15. Bohren MA, Hofmeyr GJ, Sakala C, Fukuzawa RK, Cuthbert A. Continuous support for women during childbirth. Cochrane Datab Sys Rev 2017.

16. Dolatin M, Hasanpour A, Heshmat R, Alavi H. The effect of reflexology on pain intensity of labour. J Zanian Univ Med Sci Health Serv 2011; 18: 52-61.

17. Smitha JS, Bindu CG. Effect of foot reflexology on labour pain during the first stage of labour. Glob J Res Anal 2015; 4: 136-137.

18. Blunt E. Foot reflexology. Holist Nurs Pract 2006; 20: 257-259.

19. Belal G. Efficacy off acupressure on pain intensity during the first stage of labour. Thesis, Faculty of Nursing, Tanta University 2006.

20. Eman G. Efficacy of reflexology on first stage labour pains. J Health Med Nurs 2015; 18: 53-64.

21. Hoeger Bement M, Weyer A, Keller M, Harkins AL, Hunter SK. Anxiety and stress can predict pain perception following a cognitive stress. Physiol Behav 2010; 101: 87-92.

22. McNeill JA, Alderdice FA, McMurray F. A retrospective cohort study exploring the relationship between antenatal 
Comparison of the effect of control, presence of a skilled birth attendant and reflexotherapy on labour outcomes in terms of pain, duration of labour and birth satisfaction among primigravid women-a pilot study

reflexology and intranatal outcomes. Compl Ther Clin Pract 2006; 12: 119-125.

23. Alehagen S, Wijma B, Wijma K. Fear of childbirth before, during, and after childbirth. Acta Obstet Gynecol Scand 2006; 85: 56-62.

24. Yildirim G, Sahin NH. The effect of breathing and skin stimulation techniques on labour pain perception of Turkish women. Pain Res Manag 2004; 9: 183-187.

25. Abd ElFattah H, Metwaly S, Khedr N. Outcomes of foot reflexology on the pain and certain features of the labor for the primiparous women. Life Sci J 2015; 12: 206-216.

\section{*Correspondence to}

Mathew Jijimole

Department of Obstetrics and Gynaecological Nursing

Little Flower Hospital and Research Centre

Kerala

India 